under the auspices of the institutions above named and the State Factory Investigation Commission.

3. The interests of chemists in devising means to render dangerous chemical trades less hazardous. Already much has been accomplished in the modern improvements in the manufacture of phosphorus matches, the elimination of lead from pottery glaze and of arsenic pigments from the coloring of wall papers, artificial flowers, etc. In France, the compulsory substitution of zinc for lead white in the manufacture of paint has accomplished great good.

4. The education of manufacturers and employers in the knowledge of the economic efficiency which immediately results from the adoption of recognized methods of proper ventilation and cleanliness in foundries, mills or factories where toxic fumes, gases, vapors or dusts are generated.

5. The education of employees in hazardous chemical trades as to the special dangers involved and simple expedients to avoid them. Such a system of instruction as that practiced by the Illinois Steel Corporation, in methods of avoidance of accidents, if applied to the avoidance of disease hazards, would soon demonstrate an equal if not greater economic value. These measures, upon which this corporation finds it an economy to expend over $\$ 1,000,000$ annually, comprise furnishing workmen with printed directions, display of special danger signs, offering of rewards for compliance with regulations, the formation of committees of safety among the workmen, and many other expedients.

I see no reason why there should not be warning labels attached to the containers of paints, varnish and volatile chemical irritants of all kinds, just as we now have compulsory labeling of the contents of all containers of dangerous drugs. Such labels should state concisely the name of the hazardous chemical, the chief symptoms it produces, and the means of avoiding the hazard. For example, such a label might read: "WARNING! This paint contains lead. If the lead reaches the mouth by means of unclean hands, food or tobacco, poisoning may result with symptoms of colic, paralysis, hardening of the arteries, or chronic kidney disease. BE CAREFUL!" or "WARNING! This varnish contains wood alcohol, the fumes of which, if breathed in a confined space, may cause permanent blindness, or possible fatal paralysis of the heart. Use only where there is good ventilation, and never breathe the fumes directly." Of course, in this case the use of wood alcohol should be prohibited altogether, but such a label might have saved the lives and eyesight of those unfortunate men in the brewers' vats in Buffalo.

6. The periodic examination by physicians of workmen using dangerous chemicals, conducted at least as often as once a month, in order to detect incipient cases of poisoning and give proper suggestions as to prevention of further hazards.

I have presented only a brief review of a very broad and most important topic, which is just beginning to attract the study and interest in this country which it has commanded abroad for many years. It is a topic which appeals alike to humanitarian, scientific and purely economic interests, for there is no one among us who does not make use of some article of necessity, adornment or luxury which has in its process of manufacture been associated with possibility of disease hazard to the workman, from the match with which we strike a light, to the glaze on our porcelain coffee cup, or the felt hat which we "throw into the ring." The problem before us is to make first a rational study of the extent and gravity of the various occupational disease hazards, and then seek to deal with them through education, invention, common-sense precaution, and, where all else fails, through appropriate legislation.

\section{THE PROGRESS OF THE WORK ON THE REVISION OF THE UNITED STATES PHARMACOPOEIA. ${ }^{2}$}

By J. P. REMINGTON.

The American Chemical Society, having representation in the United States Pharmacopoeial Convention, should be kept informed of the progress made from time to time in the work of revision. The subcommittee on scope have been wrestling with the problem of admissions and deletions for over one year. Their labors cannot be said to be concluded, for, although they have presented a tentative list, some modifications will be required. The convention recommended publicity under Section $\mathrm{I}_{4}$ in the Abstract of Proceedings in the following words: "It is recommended that the General Committee of Revision make public, for comment and criticism, an abstract of new descriptions and standards and of changes in descriptions and standards proposed, before final adoption."

Inasmuch as admissions and deletions would be properly included, the Committee of Revision decided to give the lists to the journals for publication. The lists have excited considerable comment and the chairman has received many communications advising the admission of this, and that, and the other, or the deletion of this, and that, and the other. The committee itself, although reasonably harmonious, are divided on the scope of the Pharmacopoeia. A small but active minority have clearly expressed the view that the Pharmacopoeia contains a large number of articles which, in their opinion, are worthless. On the other hand, a large majority of the committee are opposed to dropping so many drugs and medicines because they say they are still used in the practice in various parts of the country, and as the Pharmacopoeia is now a book of standards, they believe that the doctor and the pharmacist are entitled to have the benefit of the best quality of drugs and preparations and that this consummation will be brought about most effectually by retaining the drug or preparation in the Pharmacopoeia and attaching definitions, descriptions, and tests, so that those who do use the article may have the protection of the National and State Food and Drug Laws. It seems difficult at times for some of the members of the committee to realize that the Pharmacopocia is intended to represent all parts of the United States and that there always will

1 Chairman's address delivered before the Division of Pharmaceutical Chemistry, American Chemical Society, December, 1911. 
be in the Pharmacopoeia many preparations which a doctor has never used and probably never will use in his life. It does not follow, however, that some other physician living in a different section of the country has not found the medicine rejected by Dr. A a most efficient remedy and Dr. B could argue with just as much force that he has no use for the pets recommended by $\mathrm{Dr}$. A. This situation is a perfectly natural one and will not embarrass the committee.

So far, there has not been the slightest attempt on the part of the manufacturers of specialties protected by trade mark or copyrighted label or controlled by proprietary rights to have their goods introduced into the Pharmacopoeia. In former revisions there were slight evidences of the pride of a manufacturer to have his product paid the compliment of Pharmacopoeial recognition, but since the passage of the Food and Drug Laws it would seem that the manufacturer preferred to get along without official recognition, for this would mean that he must always maintain his product at the standard of strength and quality once established by the Pharmacopoeia.

This does not mean that he would like to lower the quality; he might want to improve it by raising the standard, or the Pharmacopoeial test for it might prove inadequate or faulty. In any event he would prefer freedom of action.

Analytical chemistry has proved to be one of the foundation stones in the building of reform structures. Without it, successful prosecution of offenders could not be maintained. The chemist has risen immensely in reputation in the eyes of the public. The labels of the manufacturer must now represent the truth in describing the contents of the container. False and misleading statements are no longer tolerated. This puts the honest manufacturer in the proper light. Advertising artists with imagination have prepared labels attractive to the eye in the past and they are still exploiting preposterous claims of remedies, but much more intelligence is being displayed by the public. Nowadays it is amusing to listen to the remarks of young people who ask their elders whether this or that statement in an advertising circular is really true or likely. The old idea that so many people used to have, that because a statement was in print it must be "gospel truth," is becoming obsolete. Probably no other influence has been so great in improving the quality of chemical preparations as the requirement of the Food and Drugs Act, that, if an article labeled with an official name differs in quality or strength from the standards laid down in the United States Pharmacopoeia, such difference must be distinctly printed on the label. A manufacturer in nine cases out of ten prefers to improve his product and bring it up to the official standard rather than place upon the label a qualifying statement.

The tests in the Eighth Revision of the chemical substances are undergoing careful investigation, and a number of the old tests will be deleted and new ones admitted. The sub-committee on organic and inorganic substances have their hands full at the present time in trying out the many suggestions which have come to them; it is this part of the work which will probably delay the issue of the book. Much time has been consumed in selecting the simplest and most effective methods for determining the physical factors, i. e., melting points, boiling points, solubilities, specific gravities, saponification values, iodine numbers, etc. It is obvious that in a law book it is necessary to designate uniform methods for obtaining these physical factors. The figures given in the text of the book would show that they were obtained by the methods given in the book in the Introductory Notices. The question of solubilities seems to be the most difficult, as might be supposed, and the work of revising all the solubilities in the text according to the Official Method will call for much labor and time.

Every one of the sub-committee has been industrious and active, but so far, the sub-committee on nomenclature have not been called upon for their report. This is usually the last sub-committee to send in its recommendations. A number of letters have been received by the chairman urging the necessity for retaining the present system of nomenclature.

While there may be some members who desire to introduce changes, it is believed that the majority of the committee are opposed to radical changes. Of course, these members will listen attentively to all suggestions. When it is considered that millions of labels of official products are now in use and a large sum of money has been expended very lately in revising these to conform to the provisions of the law, it is believed that it would not be wise to make any change in the general form and style. But obviously any errors must be corrected, and new drugs, chemicals, or preparations introduced must have corrected titles which conform in style with those already introduced. Undoubtedly some of the names will be shortened for the sake of conciseness and convenience in printing. Abbreviations of the official titles will be introduced for the first time in the new Pharmacopoeia. These will serve as a guide to physicians and to pharmacists in labeling their stock bottles and containers.

Inasmuch as the Pharmacopoeia is now a law book, it has been proposed to print a small numeral on the left hand side of each line of the article completely down the page so that for convenience of reference one who quotes the Pharmacopoeia can indicate the page and the numbered line.

On the whole, it may be said that the work is being pushed most actively. A proper sequence and system is necessary if the valuable time of the members is not to be wasted. The immediate work of revision is entrusted to fifteen members selected by the general committee. This is called the Executive Committee of Revision and each member is chairman of a subcommittee. He and the other members of the subcommittees are chosen for their fitness to serve under their chairman. When a sub-committee is ready to make its report, the Executive Committee votes upon it and the text of the book will be framed upon the results as reported. It will be seen that, by this plan, the large number of facts accumulated in ten years 
will receive minute and careful consideration by the whole Committee of Revision and probably ninety per cent. of the final work will stand as reported by these experts. If the sub-committee should make a mistake or an error in judgment, it will be pointed out by some member of the Executive Committee and a reconsideration by the sub-committee asked for. If the whole Executive Committee and the special subcommittee should differ on any question, the Executive Committee has the right under the By-Laws to appeal to the fifty-one members of the General Committee of Revision for final statement. Then again, under the plan of publicity, any one interested in the Pharmacopoeia may comment through the journals or appeal to the chairman of the Committee of Revision for a reconsideration. This plan, which differs from that used in the previous edition, is working out satisfactorily: it is constructive work on a comprehensive plan. The new Pharmacopoeia will not represent one man's work, but the best judgment of men selected by a large convention for their special fitness to perform certain duties. A Pharmacopoeia should represent as accurately as possible the present state of knoreledge and a committee should not delay the publication of the work because some one believes he has discovered a new test or an improvement and all must wait until such has been tried out.

In the past a number of tests were introduced into the Pharmacopoeia which had not been sufficiently tried out by many workers. The result sometimes proved to be unsatisfactory and an old test had been discarded in favor of a new one which had practically failed. Therefore it would seem to be common sense to "hold fast that which is good." A Pharmacopoeia should represent advanced knowledge of facts known and proved at the time the book is written. There should be no guess work or hope-so's. It is far better to take no chances on an untried test, no matter how promising it may seem to be; but now that the book is the standard for the country, it is of the utmost importance that the definitions, descriptions and tests should be selected from facts which are tried and true.

The members of the American Chemical Society are requested to send at once to the office of the chairman of the Committee on Revision, ${ }^{8} 8_{3} 2$ Pine Street. Philadelphia, any correction or suggestion which they believe will improre the present Eighth Revision of the United States Pharmacopoeia. These letters are referred first to the sub-committee having such subject in charge. They are then carefully treated under the plan outlined above and it is not likely that any comment or suggestion could be overlooked. Of course, no one can promise that every suggestion will be adopted, for many of the suggestions upon the same subject are opposed to each other. In some cases two tests for the same substance have been suggested, both of which are valuable. It then becomes the duty of the committee to choose between them, and this responsibility must be assumed by the committee. Outside assistance from experts will be freely sought. Some one who has made an especial study of an assay or the habitat of a plant, or some manufacturer, who is willing to disclose special information which he may have, will find the committee responsive and eager to accept whatever is tried and true.

Now is the time to send in all suggestions for improvement. Unfavorable criticism of the printed book will be shorn of its sting. If any one interested in the new revision holds aloof and deprives the committee of a valuable fact or hint which he has discovered, it will tend to depreciate the value of the Ninth Revision. The plan of revision is comprehensive and the system is the best that could be devised by representative convention in which no special interest has been recognized and which is not under the domination of any trust or clique.

The conclusions of the committee will be published in advance and no corporations or firms will have any privileges which would tend to give them any financial advantage over any other firm or corporation. Neither the chairman of the committee nor, as far as he knows, any other member has been approached by any one seeking such an advantage. This is undoubtedly due to the fact that advance information has gone abroad that it would be useless for any one to attempt to obtain special privileges which would be denied to others. Investigation will always prove that the confidence and the trustworthiness of the members of the Committee of Revision are well placed.

Finally, let me appeal to the members of this Society to cheerfully render every assistance in order that the new Pharmacopoeia may be the best book of its kind in the world.

\section{CURRENT INDUSTRIAL NEWS}

THE INDUSTRIAL USES OF OZONE.

In a paper on the production and application of ozone, in a recent number of Nature (88, No. 2208, pp. 551-5), F. Mollwo Perkin states that the only method employed commercially to prepare this powerful oxidizing agent is to subject oxygen to the action of the silent electric discharge, the oxygen thereby receiving electrical energy and becoming converted into ozone. Since all the apparatus employed depends upon some method or other of obtaining such a discharge, very high electrical potential is necessary. In general, the silent discharge occurs between conducting plates separated by means of a dielectric. The original ozonizer of this type was the invention of $W$. von Siemens; it consisted of two concentric tubes, coarcd on their outside surfaces with tinfoil, the glass of the tubes acting as the dielectric. Berthelot employed glass as the dielectric and a liquid as the conducting material. Modifications of both these forms are now used commercially. The "Ozonair" apparatus consists of wire gauze as the conductor, separated by mica as the dielectric. When the ozone is to be produced for water sterilization-now actually employed commercially-the 